\title{
Ameliorative Effects of Enriched Environment and Chronic Administration of Aqueous-methanol Extract of Garlic (Allium sativum) on Mice Models of Depression
}

\author{
P. P. Mshelia ${ }^{1^{*}}$, M. I. A. Saleh ${ }^{1}$, O. O. Omodara ${ }^{1}$ and A. A. Madaki ${ }^{1}$ \\ ${ }^{1}$ Department of Human Physiology, Faculty of Basic Medical Sciences, College of Medical Sciences, \\ Abubakar Tafawa Balewa University, Bauchi, Nigeria.
}

Authors' contributions

This work was carried out in collaboration among all authors. Author PPM and MIAS designed the experiment, carried it out, analyzed the data and write the manuscript; author OOO was involved with experimentation and literature search while author AAM also was involved in experimentation. All authors approved the final manuscript.

Article Information

DOI: 10.9734/ARRB/2021/v36i230340 Editor(s):

(1) Dr. Md. Torequl Islam, Federal University of Piaui, Brazil. Reviewers:

(1) Abu Montakim Tareq, International Islamic University Chittagong, Bangladesh (2) Gerardo Abraham Fridman, University of Buenos Aires, Argentina. Complete Peer review History: http://www.sdiarticle4.com/review-history/65871

Original Research Article

Received 03 January 2021

Accepted 07 March 2021

Published 25 March 2021

\section{ABSTRACT}

Depression is a state of mood or energy level that includes lack of motivation, a sense of hopelessness and a loss of physical energy. The World Health Organization revealed that depression is one of the leading causes of ill health and disability worldwide. More than 300 million people are living with depression. Many of the currently available antidepressant drugs have proven to be effective but they are burdened with some disadvantages such as various adverse effects, problematic interactions and relatively low response. Therefore the need to utilize a natural agent in the management of depression is paramount. The aim of this study was to investigate the effects of chronic administration of extract of Allium sativum and Enriched environment in depression. 42 albino mice were used and divided into seven groups of five mice each. Group 1 was given distilled water; groups 2 and 3 received $200 \mathrm{mg} / \mathrm{kg}$ and $400 \mathrm{mg} / \mathrm{kg}$ of aqueous extract of Allium sativum respectively; while groups 4 and 5 were in addition to receiving $200 \mathrm{mg} / \mathrm{kg}$ and 400 
$\mathrm{mg} / \mathrm{kg}$ of the extract, housed in an enriched cage. Group 6 was only housed in an enriched cage and group 7 receives $10 \mathrm{mg} / \mathrm{kg}$ of imipramine. The experiment lasted for six weeks after which Force Swimming Test, Tail Suspension Test and Sucrose Preference test were conducted. The mice were sacrificed and their brain isolated, homogenized and centrifuged. The supernatant was used for biochemical assays (MDA, SOD, GPx, BDNF \& TNF- $\alpha$ ). The results showed that Allium sativum and Enriched Environment helped in mitigating depressive disorders. Therefore, conducive environment and garlic extract could be used in the management of depression.

Keywords: Depression; Allium sativum; environmental enrichment; mice.

\section{INTRODUCTION}

The World Health Organization (WHO) revealed that depression is one of the leading causes of ill health and disability worldwide. More than 300 million people are living with depression, an increase of more than $18 \%$ between 2005 and 2015. It is exceeded by lower respiratory infections, perinatal conditions and HIVIAIDS $[1,2]$. Two-third of depressed patients experience suicidal thoughts and $10-15 \%$ of them attempt suicide [3]. At its worst, depression can lead to suicide [1]. It is a state of mood or energy level that includes lack of motivation, a sense of hopelessness and a loss of physical energy. It is an emotional status that can result from many parts of our life. It is a debilitating disease that affects a person's work, family, sleeping and ability to assess life [4,5]. A state of constant depression may suggest a biochemical imbalance or continual stress [4]. Depression is different from usual mood fluctuations and shortlived emotional responses to challenges in everyday life [1].

The main symptoms of depression are due to functional deficiency in the levels of monoaminergic transmitters, noradrenalin, 5hydroxytriptamine and dopamine in the brain [6]. Drugs that increase the level of these neurotransmitters in the Central Nervous System (CNS) show antidepressant activity [7]. Noradrenergic and dopaminergic systems (monoaminergic neurotransmission) are precisely associated with pathogenesis of depression, and should be therefore considered as valuable targets in patients' treatment. Therefore the major antidepressant therapies aim for an enhancement in the transmitters levels in the neurons and thus normalize the neurotransmission $[8,9]$.

Depression is a common disorder with increasing lifetime rates [10]. It is often a debilitating disease that affects a person's work, family, sleeping and ability to assess life. Despite the advances in the treatment of depression with selective serotonin reuptake inhibitors (SSRIs) and serotonin and norepinephrine reuptake inhibitors (SNRIs), there continue to be many unmet clinical needs with respect to both efficacy and side effects [4].

Many of the currently available antidepressant drugs have proven to be effective but they are burdened with some disadvantages such as various adverse effects, problematic interactions and relatively low response [11]. In addition, it is also reported that only two out of three patients respond to any given treatment and, of these, one would probably have responded to placebo alone [12]. On the other hand, drugs obtained from natural sources have good efficacy, least risk and low side effects profile. Recently, the search for novel pharmacotherapy from medicinal plants for psychiatric illnesses has progressed significantly. Therefore, herbal therapies should be considered as alternative or complementary medicines [13]. Hence there is an increasing interest in total medicinal plant extracts, the largest value of which may be due to its constituents that subscribe to the modulation of the oxidative balance in vivo. Additionally, the special importance of total plant extracts is that they are easily available products, without purification to apply them in possible prevention of diseases [14].

Oxidative stress is a condition of imbalances between oxidants and antioxidants. Numbers of evidences are supporting the involvement of oxidative and nitrosative stress in the pathophysiology of Major Depressive Disorder. Many of the negative effects of oxidative stress are decreased after supplementation with dietary antioxidants $[15,16,17,18]$. Medicinal plants have been utilized in the treatment of ailments for many years in different aboriginal medicine as well as folk medicine [19]. Over the centuries, garlic has acquired a special position in the folklore of many cultures as a formidable prophylactic and therapeutic medicinal agent [20]. Garlic and its preparations have been 
widely recognized as agents for prevention and treatment of cardiovascular and other metabolic diseases, atherosclerosis, hyperlipidemia, thrombosis, hypertension, dementia, cancer and diabetes $[19,21]$. It has been reported to possess anti-stress, anti-ageing, memory improving properties and has the potential for preventing the progression of Alzheimer's disease $[22,23,24]$. Garlic has antibiotic, anti-cancer, antioxidant and anti-inflammatory properties; it can lower blood sugar levels and has protective effects on the cardiovascular. Furthermore, it is cheaper than many chemical drugs and easily accessible; therefore, it is generally better accepted by the patients resulting in a higher compliance rate. Garlic has neuroprotective effects attributed to its three interrelated antiatherogenic, antioxidant and anti apoptotic properties $[25,22,26]$.

Neurotrophic factors are critical regulators of the formation and plasticity of neuronal networks. Brain-derived neurotrophic factor (BDNF) is abundant in the brain and periphery, and is found in both human serum and plasma. Studies have indicated that serum or plasma BDNF levels are decreased in untreated major depressive patients. Antidepressant treatment for at least four weeks can restore the decreased BDNF function up to the normal value. Antidepressant treatment promotes increased BDNF activity as well as several forms of neuronal plasticity, including neurogenesis, synaptogenesis and neuronal maturation [27]. Tumor necrosis Factor (TNF- $\alpha$ ), a pro-inflammatory cytokine, increases in chronic disease conditions leading to depression. Therapy inhibiting TNF- $\alpha$ reduces depression in people with chronic disease [28].

The common animal model of depression is Forced swimming test (FST) because it induces a depressive-like manner to conceal antidepressant effect of chemicals and can conclude depressive-like behaviour in rats after exposure to other stressors. FST explains a stressing situation which capable of creating a state of lower habit, reflected in the motionlessness induced in animals. The suggested mechanism by which stress causes its effects is via the hypothalamic-pituitary-adrenal axis and/or via the sympathoadrenomedullary system [29].

Environmental enrichment (EE) influences the frequency and diversity of positive natural behaviour, decreasing the occurrence of abnormal behaviour [30]. Enriched rats usually show a superior ability to adapt or cope, when a situation is highly conflicting or stressful and has to be solved by using complex strategies [31,32]. Enriched housing has a positive effect on the immune system and can be hypothesized to act directly to enhance, or indirectly to buffer, the immune system upon exposure to an acute environmental or pharmacological challenge $[33,34]$. Also EE has been shown to promote plasticity and to protect against CNS insult. Neurogenesis by enrichment is promoted in adult rat hippocampus [35]. Some studies have demonstrated that EE can ameliorate stressinduced depressive-like behaviours [36].

\section{METHODOLOGY}

\subsection{Extract Preparation}

Fresh garlic (Allium sativum), was purchased from a local grocery store. The fresh garlic was air-dried, grinded into powder. Extraction was carried out using cold maceration with occasional shaking for $72 \mathrm{hr}$ using $500 \mathrm{ml}$ of $70 \%$ aqueous methanol for each $100 \mathrm{~g}$ of powdered material. Total of $300 \mathrm{~g}$ of garlic powder was used in $1.5 \mathrm{~L}$ of aqueous methanol. The extracts were concentrated in vacuo and subsequently referred to as aqueous methanol extract. The ratio of methanol $(70 \%)$ to aqueous $(30 \%)$ was $2: 1$ [37].

\subsection{Acute Toxicity Study}

Locke's method as described by [38] was used. It has two phases. In phase one, nine mice were divided into three groups of three mice each and administered with different doses (10, 100 and $1000 \mathrm{mg} / \mathrm{kg}$ ) of the aqueous methanol extract of the garlic. They were observed for 24 hours to monitor their behaviours as well as mortality. While in phase two, three mice were divided into three groups of one mice each and administered higher doses $(1600,2900$ and $5000 \mathrm{mg} / \mathrm{kg}$ ) of the garlic extract and observed again for 24 hours.

Then the $L D_{50}$ was calculated by the formula:

$$
L D_{50}=\sqrt{ }\left(D_{0} \times D_{100}\right)
$$

$D_{0}=$ Highest dose that gave no mortality,

$D_{100}=$ Lowest dose that produced mortality.

\subsection{Phytochemical Screening}

The extract was tested for the presence of the phytochemicals, Saponin, Tannins, Flavonoid, Alkaloid, Steroid, Terpenoid and Anthraquinone using the method described by [39]. 


\subsection{Experimental Protocols}

Forty two (42) male albino mice was purchased at the Gombe State University Department of Physiology Animal House, transported and housed in plastic cages at the animal house of the Department of Biological Sciences, Abubakar Tafawa Balewa University, Bauchi. After acclimatizataton, they were divided into seven groups of six mice each. Group 1 was given distilled water; groups 2 and 3 received 200 $\mathrm{mg} / \mathrm{kg}$ and $400 \mathrm{mg} / \mathrm{kg}$ of aqueous methanolic extract of Allium sativum respectively; while groups 4 and 5 were in addition to receiving 200 $\mathrm{mg} / \mathrm{kg}$ and $400 \mathrm{mg} / \mathrm{kg}$ of the extract, housed in an EE cage. Group 6 was only housed in an EE (enriched cage) and group 7 receives $20 \mathrm{mg} / \mathrm{kg}$ of imipramine hydrochloride (Kayhelt Pharmaceutical Ltd, Jos, Nigeria). The experiment lasted for six weeks after which the mice were subjected to behavioural tests and biochemical assays.

\subsection{Enriched Environment}

Ferplast rodent cage was purchased from Amazon, USA used for the test as an EE. Enrichment was defined in terms of physical environment and not social housing [40]. The cage and consisted of coloured platforms, rodent tunnels, a ball, toys and a running wheel. A water bottle was suspended above the ceiling of the cage and food pellets was provided on the floor. For housing conditions the sawdust of the cage was changed once a week [41].

\subsection{Force Swimming Test}

The forced swimming test (FST) was for a period of two days and was carried out as a slight modification to the method of [42]. Rectangular glass cylinder of height $45 \mathrm{~cm}$ and diameter $20 \mathrm{~cm}$ was used. It was filled with water to the $15 \mathrm{~cm}$ mark (maintained at $21-23^{\circ} \mathrm{C}$ ). On the first day, the animals were introduced into the glass cylinder and forced to swim for period of $15 \mathrm{~min}$ until they became exhausted, then they were removed, dried and returned to their cages. On the second day, the animals were subjected to the same test 30 minutes after administration of the garlic extract $(200 \mathrm{mg} / \mathrm{kg}$ and $400 \mathrm{mg} / \mathrm{kg}),(20$ $\mathrm{mg} / \mathrm{kg}$ ) Imipramine was used as the standard control and $(10 \mathrm{ml} / \mathrm{kg})$ distilled water as the negative control. The animals were observed for a period of 6 min ( 2 min initial adjustment and 4 min for immobility observation) and immobility time (period without swimming or moving any of its limbs) taken.

\subsection{Tail Suspension Test}

The tail suspension test (TST) was performed according to the method described by [43]. The principle of this test is that suspending mice upside down leads to characteristic behaviour immobility which resembles human depression. Mice were considered immobile when they hanged passively and completely motionless [44]. Each mouse was suspended by an adhesive tape attached $1-2 \mathrm{~cm}$ from the tip of their tail to a horizontal bar for 30 minutes after the administration of the test substances. The bar was raised $50 \mathrm{~cm}$ from the floor, the mice were observed for a period of 6 minutes $(2 \mathrm{~min}$ initial adjustment and $4 \mathrm{~min}$ for immobility observation) and the immobility time (Total exposure time - Mobility time) was recorded with the aid of a stop watch. At the end of the experiment the tape was removed and the mice were returned to their cages.

\subsection{Sucrose Preference Test}

The sucrose preference test (SPT) as described by [45] was employed. This is a reward-based test, used as an indicator of anhedonia or the decreased ability to experience pleasure, which represents one of the core symptoms of depression. Rodents are born with an interest in sweet foods or solutions. Reduced preference for sweet solution in SPT represents anhedonia, while this reduction can be reversed by treatment with antidepressants. SPT was carried out in the animal's home cage. For the SPT, mice were presented with 2 dual bearing sipper tubes. One tube contained plain drinking water, and the second contained a sucrose solution. Water and sucrose solution intake was measured daily. Sucrose preference was calculated as a percentage of the volume of sucrose intake over the total volume of fluid intake and averaged over testing period.

\subsection{Biochemical Analysis}

\subsubsection{Animal sacrifice and tissue processing}

At the end of the behavioural studies, the mice were fasted overnight and subsequently anaesthetised with combination of ketamine (75 $\mathrm{mg} / \mathrm{kg}$ ) and diazepam (5 $\mathrm{mg} / \mathrm{kg}$ ) administered intramuscularly (im). They were dissected and the brain removed and washed in phosphate- 
buffered solution $(\mathrm{pH} 7.4)$. Some brain tissues were homogenised with phosphate-buffered solution, centrifuged at $447 \times \mathrm{g}$ for approximately $20 \mathrm{~min}$. The supernatant was carefully collected and used for the ELISA kit assays.

\subsubsection{ELISA kits techniques}

Malondialdehyde (MDA) ELISA kits, glutathione peroxidise (GPx) assay ELISA kits, Superoxide dismutase (SOD) ELISA kits, Tumour necrosis factor (TNFa) ELISA kits and Brain derived neurotrophic factor (BDNF) ELISA kits was purchased from FineTest Biotech company limited, Wuhan, Hubei, China. The assay was done following the manufacturer's manual based on the principles of each of the test. ELISA microplate reader was used to read the absorbance and the concentration of the solutions.

\subsection{Data Analysis}

All data obtained was analysed with SPSS version 23 using one way ANOVA followed by Tukey post hoc test and expressed as Mean \pm SEM. Values with $\mathrm{P}<0.05$ was considered statistically significant.

\section{RESULTS AND DISCUSSION}

The result of the phytochemical screening of aqueous methanol extract of garlic showed the presence of Saponin, Tannins, Flavonoid, Terpenoid and Anthraquinone. And for the acute toxicity testing, the result achieved showed that the garlic extract is relatively safe without mortality even at $5000 \mathrm{mg} / \mathrm{kg}$ of animal. However the dosage of $200 \mathrm{mg} / \mathrm{kg}$ and $400 \mathrm{mg} / \mathrm{kg}$ were used.

The FST result (Fig. 1) showed that aqueous methanol extract of Allium sativum significantly reduced the immobility time in all the treated groups but more significantly in the $400 \mathrm{mg} / \mathrm{kg}$ group. There was also significant reduction in immobility time in the group kept in Enriched cage and received $400 \mathrm{mg} / \mathrm{kg}$ of the extract and the positive control (imipramine) group when compared with the negative control (distilled water) group. The group that received no intervention and housed in an enriched cage had significant reduction in immobility time when compared to the negative control (distilled water) group. Similarly there was significant reduction in immobility time in all treated groups but more significantly in the $400 \mathrm{mg} / \mathrm{kg}$ garlic extract and
EE group. The immobility displayed reflects a state of despair, lowered mood which reflects depressive disorders in humans but significantly reduced by treatment [46]. This result collaborated the findings of [47] which stated that garlic extract significantly decreased immobility time in dose-dependent manner in both TST and FST and is indicating of significant antidepressant activity (Figs. $1 \& 2$ ). And since the antidepressant - like action of the extract was comparable to imipramine (standard antidepressant), garlic extract may have therapeutic value for the management of depression probably through the inhibition of MAO-A and MAO-B levels and interacting with adrenergic, dopaminergic, serotonergic and GABAergic systems as postulated by [47]. However, this result doesn't agree with [24] who stated that processed garlic powder show no effect against stress. EE protects against the effects of chronic stress $[48,49]$.

The effect of the extract was noticeable in the SPT as it showed that mice in the distilled water group had less preference for sucrose (anhedonia) as compared to the other groups that received garlic extract and/or housed in an EE and received imipramine (Table 1). Garlic and $E E$ are factors for the reduction of anhedonia in the mice collaborating the finding of [50] that it significantly reversed sucrose preference index.

The increase in MDA concentration (Fig. 3) in negative control group (distilled water) could be due to the chronic mild stress the mice went through. The MDA concentration significantly reduced in all the garlic extract and EE groups. This is in agreement with the finding of [51] who stated that MDA level increases in predictable chronic stress. Elevated reactive oxygen species is an important mechanism in the pathophysiology of depression in rodents and humans with increase activity of SOD [52], though our finding showed no increase in SOD. There was a significant increase in antioxidant enzyme, GPx, in all treated group when compared to the distilled water group (Fig. 5). But the SOD increase wasn't statistically significant (Fig. 4). This correlate with the work of [53], who looked at the effects of chronic mild stress and imipramine on markers of oxidative stress and antioxidant system in rat liver and found no changes in SOD activity in any of the studied groups but noticed increased GPx activities [54] and also found that individual treatment with $\mathrm{EE}$ tends to up-regulate the activities of GPx. The GPx scavenges primarily 
lipid peroxides and the increase in its activity is as a compensatory response to the lipid peroxidation that might have taken place due to the chronic stress.

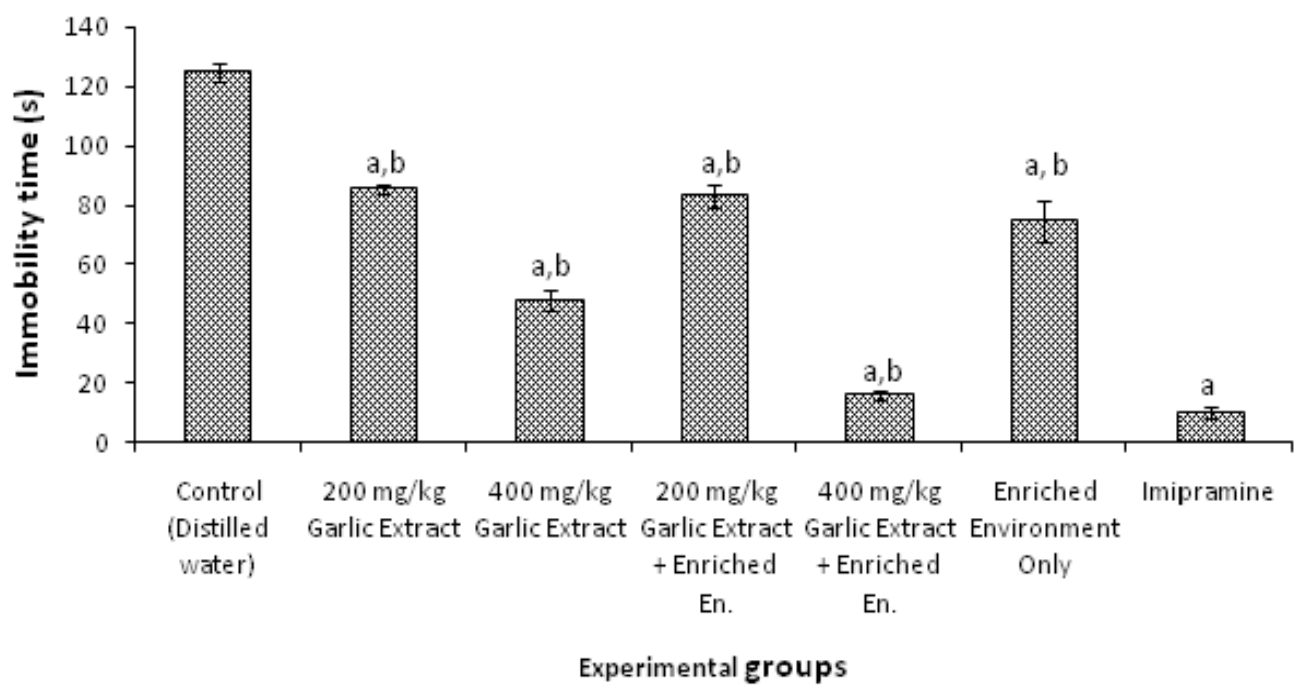

Fig. 1. Effect of chronic administration of aqueous methanol extract of garlic (Allium sativum) on the behaviour of mice in the forced swimming test (FST): data presented as mean \pm SEM; $p=0.05$ (compared with control) En = environment; $a=$ statistical significance when compared to control (distilled water) group; $b=$ statistical significance when compared to imipramine

(standard drug); $n=6$

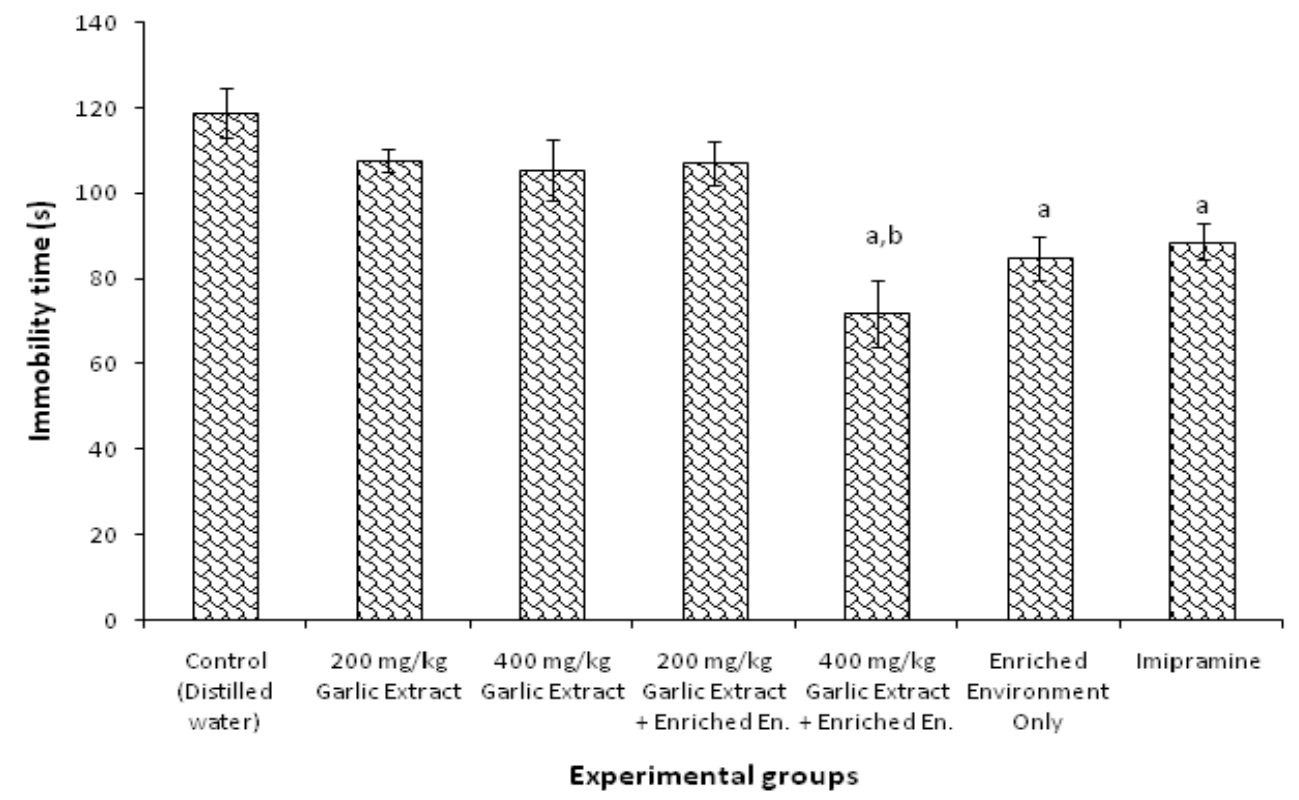

Fig. 2. Effect of chronic administration of aqueous methanol extract of garlic (Allium sativum) on the behaviour of mice in the tail suspension test (TST): data presented as mean \pm SEM; $p=0.05$ (compared with control) En = environment; $a=$ statistical significance when compared to control (distilled water) group; $b=$ statistical significance when compared to imipramine (standard drug); $n=6$ 
Table 1. Effect of chronic administration of aqueous methanol extract of garlic (Allium sativum) on the behaviour of mice in sucrose preference test (SPT): data presented as Mean \pm SEM; $p=0.05$ (compared with control), $a=$ statistical significance when compared to control (distilled water), $\mathrm{n}=6$

\begin{tabular}{lllll}
\hline Groups & Day - 1 & Day - 2 & Day - 3 & Day - 4 \\
\hline Control (Distilled water & $5.00 \pm 0.41$ & $19.50 \pm 0.50$ & $22.00 \pm 0.41$ & $25.00 \pm 1.08$ \\
$200 \mathrm{mg} / \mathrm{kg}$ Garlic Extract & $10.00 \pm 0.40$ & $20.00 \pm 1.41$ & $30.00 \pm 1.08^{\mathrm{a}}$ & $26.00 \pm 1.08$ \\
$400 \mathrm{mg} / \mathrm{kg}$ Garlic Extract & $15.00 \pm 1.22^{\mathrm{a}}$ & $15.00 \pm 1.47$ & $33.00 \pm 2.48^{\mathrm{a}}$ & $27.00 \pm 0.82$ \\
$200 \mathrm{mg} / \mathrm{kg}$ Garlic Extract & $22.00 \pm 2.16^{\mathrm{a}}$ & $30.00+0.41^{\mathrm{a}}$ & $31.00 \pm 0.82^{\mathrm{a}}$ & $32.00 \pm 0.82^{\mathrm{a}}$ \\
+ Enriched En. & & & \\
$400 \mathrm{mg} / \mathrm{kg} \mathrm{Garlic} \mathrm{Extract}$ & $30.00 \pm 0.41^{\mathrm{a}}$ & $26.25 \pm 2.87^{\mathrm{a}}$ & $35.00 \pm 1.08^{\mathrm{a}}$ & $34.00 \pm 0.41^{\mathrm{a}}$ \\
+ Enriched En. & & & \\
Enriched En Only & $15.00 \pm 0.40^{\mathrm{a}}$ & $20.00 \pm 0.41$ & $25.00 \pm 0.82^{\mathrm{a}}$ & $35.00 \pm 1.09^{\mathrm{a}}$ \\
Imipramine & $15.00 \pm 1.47^{\mathrm{a}}$ & $25.00 \pm 1.08^{\mathrm{a}}$ & $30.00 \pm 1.22$ & $30.00 \pm 0.41$ \\
\hline
\end{tabular}

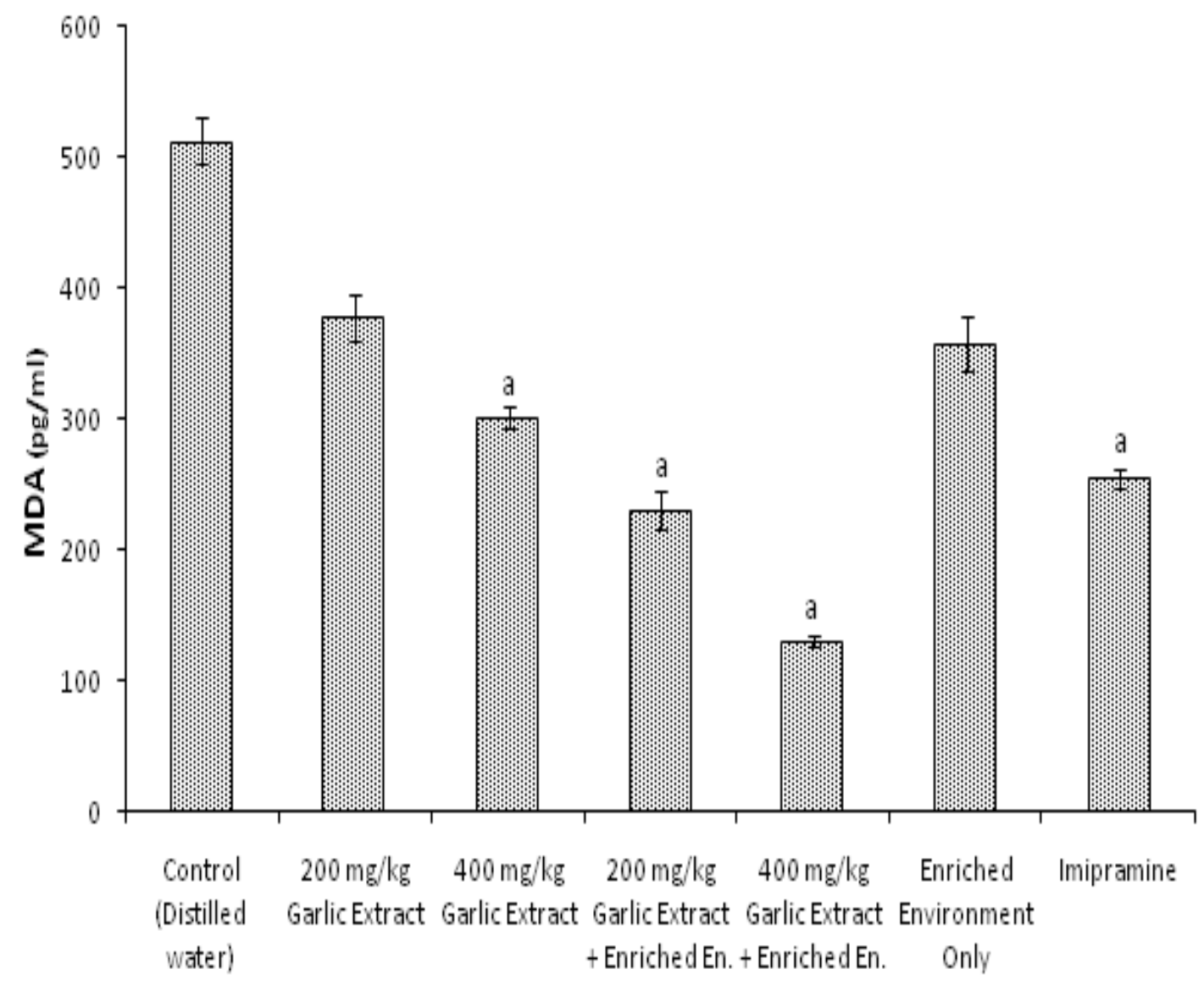

\section{Experimental groups}

Fig. 3. Effect of chronic administration of aqueous methanol extract of garlic (Allium sativum) on malondialdehyde (MDA) concentration in mice data presented as mean $\pm S E M ; p=0.05$ (compared with control) En = environment; $a=$ statistical significance when compared to control (distilled water) group; $b=$ statistical significance when compared to imipramine

(standard drug); $\mathrm{n}=6$ 


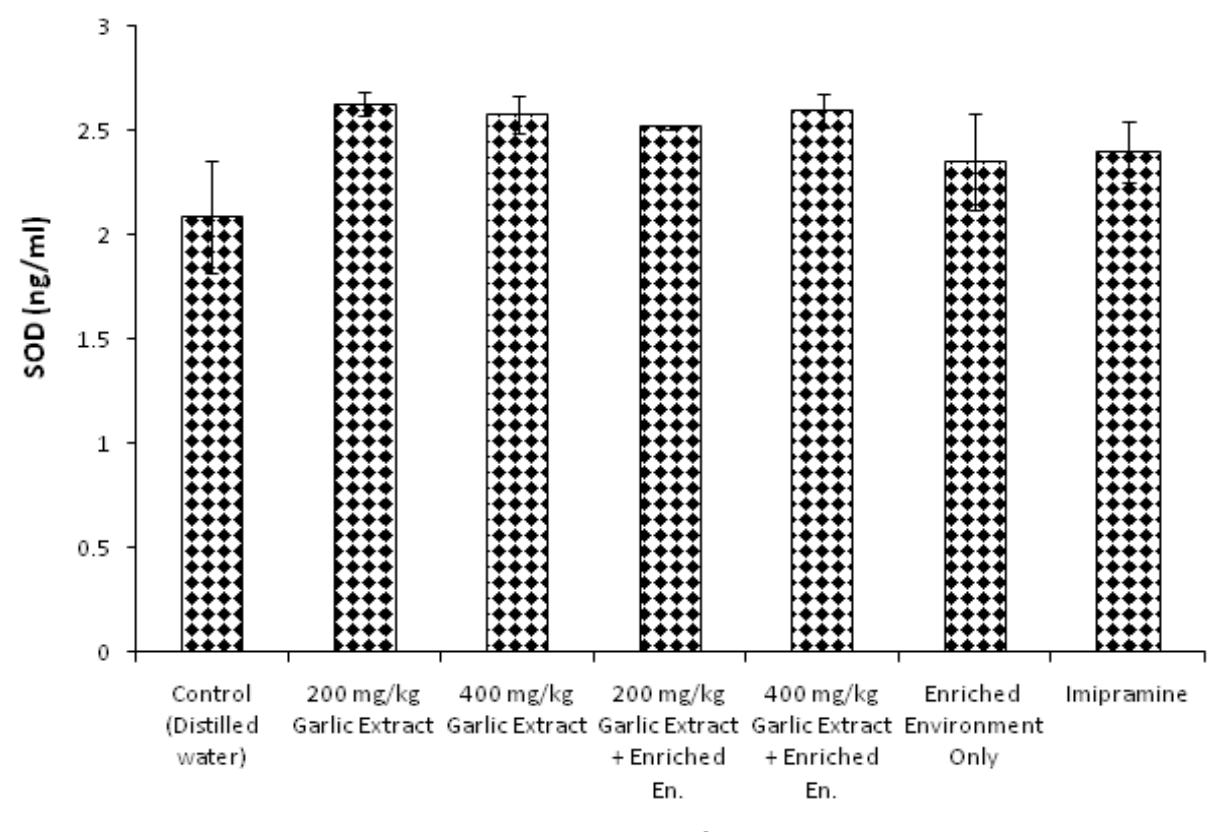

Experimental groups

Fig. 4. Effect of chronic administration of aqueous methanol extract of garlic (Allium sativum) on superoxide dismutase (SOD) concentration in mice data presented as mean \pm SEM; $p=0.05$ (compared with control) En = environment; $a=$ statistical significance when compared to control (distilled water) group; $b=$ statistical significance when compared to imipramine (standard drug); $\mathrm{n}=6$

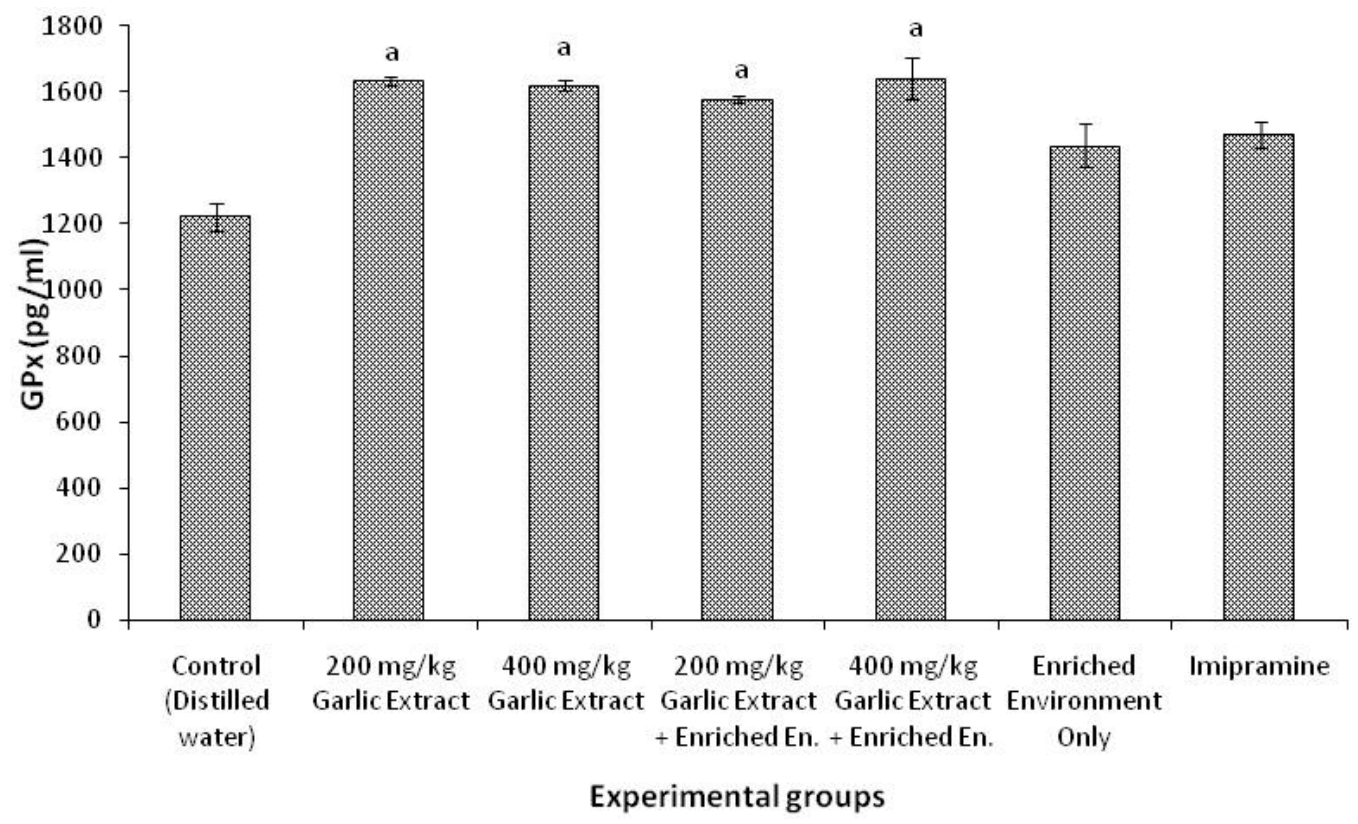

Fig. 5. Effect of chronic administration of aqueous methanol extract of garlic (Allium sativum) on glutathione peroxidase (GPx) concentration in mice. data presented as mean \pm SEM; $p=0.05$ (compared with control) En = environment; a = statistical significance when compared to control (distilled water) group; $b=$ statistical significance when compared to imipramine (standard drug); $\mathrm{n}=\mathbf{6}$ 
\$ 25000 -

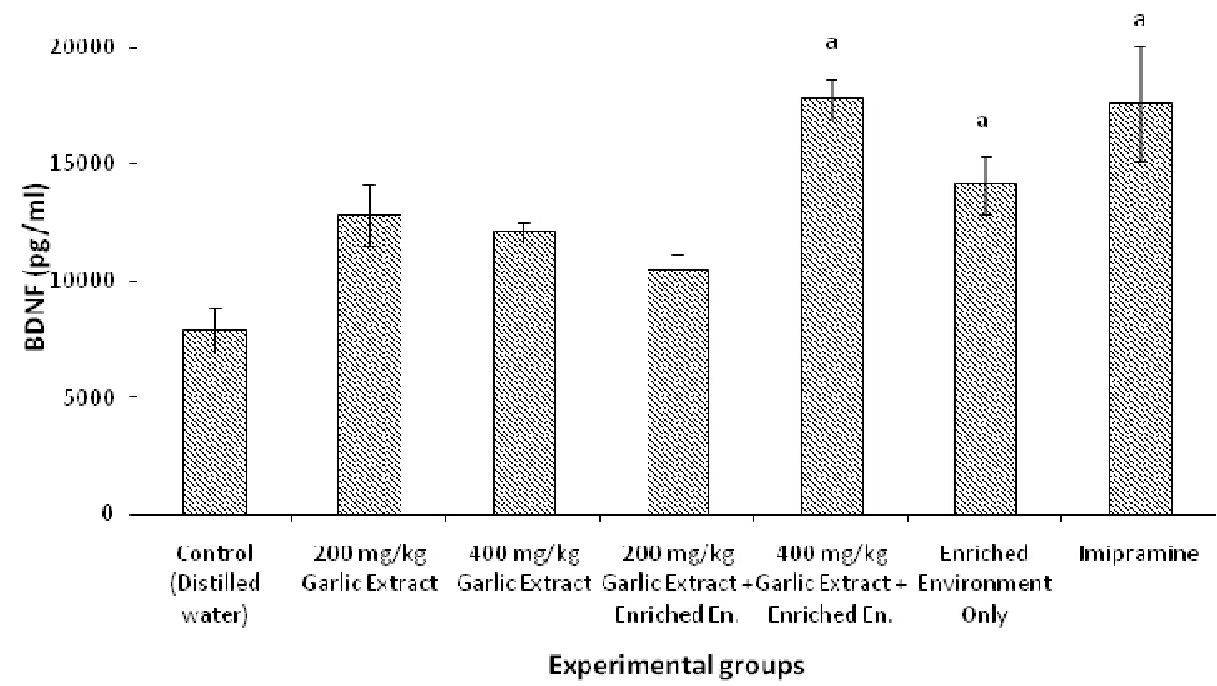

Fig. 6. Effect of chronic administration of aqueous methanol extract of garlic (Allium sativum) on brain-derived neurotrophic factor (BDNF) concentration in mice. data presented as mean \pm SEM; $p=0.05$ (compared with control) En = environment; $a=$ statistical significance when compared to control (distilled water) group; $b=$ statistical significance when compared to imipramine (standard drug); $n=6$

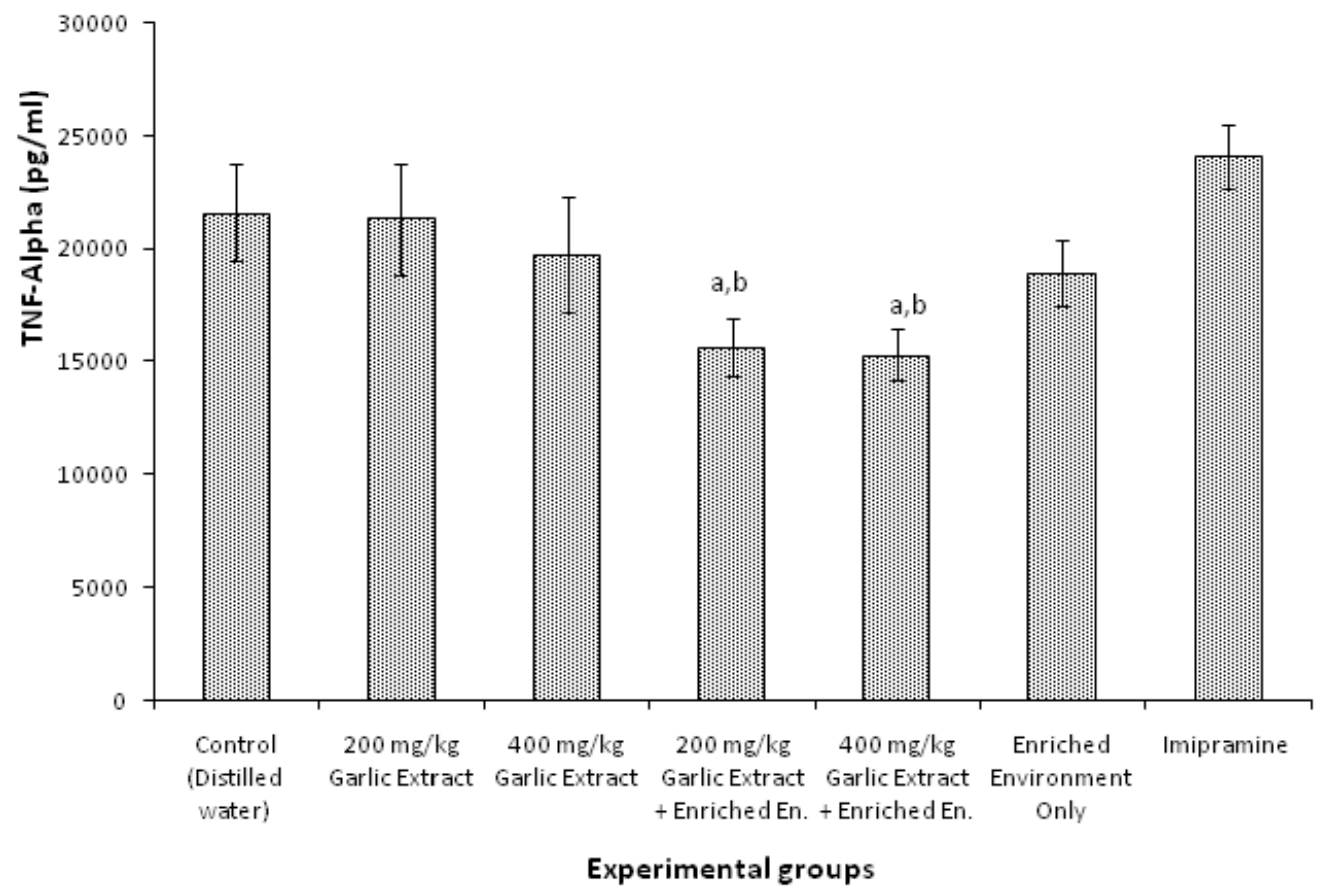

Fig. 7. Effect of chronic administration of aqueous methanol extract of garlic (Allium sativum) on tumour necrosis factor alpha (TNFa) concentration in mice. data presented as mean \pm SEM; $p=0.05$ (compared with control) En = environment; $a=$ statistical significance when compared to control (distilled water) group; $b=$ statistical significance when compared to imipramine

(standard drug); $\mathbf{n}=\mathbf{6}$ 
The effect on BDNF showed that there was significant increase in BDNF level in the EE only group as well as the $400 \mathrm{mg} / \mathrm{kg}$ with $\mathrm{EE}$ and the imipramine group (Fig. 6). And TNF-a reduced significantly in the groups that received the extract $(200 \mathrm{mg} / \mathrm{kg} \& 400 \mathrm{mg} / \mathrm{kg})$ and housed in EE. These results showed that EE, extract of alium sativum alongside EE boost the level of BDNF and this might have played a role in mitigating depression in the mice [48] in their finding stated that garlic oil significantly increase hippocampal BDNF and reversed the sucrose preference index. Just as [55] found that animal with low immobility showed significant reductions of BDNF expression. It correlates with the finding of [56] that that EE may be useful for mitigating the detrimental effects of chronic stress in patients with depression. It exerts neuromodulatory effects across species, reducing vulnerability to stress and its biochemical impact [57].

The reduction in the TNF- $\alpha$ suggests that EE and the extract might have given neuroprotection to the mice since increase in the TNF- $\alpha$ could be due to chronic unpredictable mild stress and depression-like behavior may be mediated by TNF- $\alpha$ and subsequent damage to neurons, suggesting that TNF- $\alpha$ might be an important biomarker $[58,59]$.

\section{CONCLUSION}

Mild chronic stress induces depressive behaviour in mice leading to the production of reactive oxygen species but administration of aqueous methanolic extract of Allium sativum as well as EE this ameliorates these effects. And combination of EE with aqueous methanolic extract of Allium sativum give a better amelioration as comparable with a standard drug. This suggests that garlic could be effective in the management of depression, so also enriching the environment and their combination give a better management.

\section{ETHICAL APPROVAL}

All authors hereby declare that "Principles of laboratory animal care" (NIH publication No. 8523, revised 1985) were followed, as well as specific national laws where applicable.

\section{ACKNOWLEDGEMENT}

This research was carried out with the funding support of the Tertiary Education Trust Fund (Tetfund) of the Nigerian government.

\section{COMPETING INTERESTS}

Authors have declared that no competing interests exist.

\section{REFERENCES}

1. WHO. Depression, let's talk. World Health Day, campaign; 2017. Available:http://www.who.int/campaigns/wo rld-health-day/2017/toolkit.pdf .Retrieved on $10 / 05 / 2017$

2. WHO. The World health report 2001: Mental health: new understanding, new hope.Geneva; 2001.

3. Moallem SA, Hosscinzadeh H, Ghoncheh F. Evaluation of antidepressant effect of aerial parts of Echium vulgare on mice. Iran J Basic Med Sci. 2007;10:189-196.

4. Umadevi P, Murugan S, Jennifer SS, Subakanmani S. Evaluation of antidepressant like activity of cucurbita pepo seed extracts in rats. International Journal of Current Pharmaceutical Research. 2011;3:108-113.

5. Rössler W, Salize HJ, Van Os J, RiecherRössler A. Size of burden of schizophrenia and psychotic disorders. Eur Neuropsychopharmacol. 2005;15:399-409.

6. Meyers S. Monoaminergic supplements as natural antidepressants. Altern Med Rev. 2000;5:64-71.

7. Moallem SA, Hosscinzadeh $\mathrm{H}$, Ghoncheh F. Evaluation of antidepressant effect of aerial parts of Echium vulgare on mice. Iran J Basic Med Sci. 2007;10:189196.

8. Caricati-Neto A, Bergantin LB. Novel challenges for the therapeutics of depression: Pharmacological modulation of interaction between the intracellular signaling pathways mediated by $\mathrm{Ca} 2+$ and cAMP. J Addict Ther Res. 2017;1:001-006.

9. Jithan A, Chinnalalaiah R. Synthesis and evaluation of antidepressant activity of some curcumin-like compounds. In Pharm Communique. 2009;2:38-41.

10. Elsaid FG, Alzailaie KM, Shati AA. Biochemical and molecular alterations associated with depression induced in rats. Experimental Therapeutics, Molecular Targets, and Chemical Biology. 2013;66:134-154.

11. Tamminga CA, Nemeroff CB, Blakely RD, Brady L, Carter CS, Davis KL, et al. Developing novel treatments for mood disorders: Accelerating 
discovery. Biological

psychiatry. 2002;52(6):589-609.

12. Shalam MD, Shantakumar SM, Narasu ML. Pharmacological and biochemical evidence for the antidepressant activity of the herbal preparation trans-01. Indian $\mathrm{J}$ Pharmacol. 2007;39:231-234.

13. Jintanaporn $\mathrm{W}$, Prasert $\mathrm{P}$, Kittisak S, Supaporn M, Bungorn S. Evaluation of the anxiolytic and antidepressant effects of alcoholic extract of Kaempferia parviflora in aged rats. Am J Agri Bio Sci. 2007;2:9498.

14. Dimitrios B. Sources of natural phenolic antioxidants. Trends Food Sci. Technol. 2006;17:505-512.

15. Verma AK, Bajpai A, Keshari AK, Srivastava M, Srivastava S, Srivastava R. Association of major depression with serum prolidase activity and oxidative stress. British Journal of Medicine \& Medical Research. 2017;20(4):1-8.

16. Kubera M, Obuchowicz E, Goehler L, Brzeszcz J, Maes M. In animal models, psychosocial stress-induced (neuro) inflammation, apoptosis and reduced neurogenesis are associated to the onset of depression. Progress in NeuroPsychopharmacology and Biological Psychiatry. 2011;35(3):744-759.

17. Halliwell B. Dietary polyphenols: Good, bad, or indifferent for your health? Cardiovasc Res. 2007;73:341-347.

18. NiebrAj-Dobosz I, Dziewulska D, Kwieciski $\mathrm{H}$. Oxidative damage to proteins in the spinal cord in amyotrophic lateral sclerosis (ALS). Folia Neuropathol. 2004;42:151156.

19. Beheshti F, Khazaei M, Hosseini M. Neuropharmacological effects of Nigella sativa. Avicenna J Phytomed. 2016;6(1):124-141.

20. Moyers S. Garlic in health, history and world cuisine. Suncoast Press, St Petersburg, FL. 1996;1-36.

21. Lawson LD. Garlic: A review of its medicinal effects and indicated active compounds. Phytomedicines of Europe. Chemistry and Biological activity series. 1998;691:176-209.

22. Zardast M, Namakin K, Kaho JE, Hashemi SS. Assessment of antibacterial effect of garlic in patients infected with Helicobacter pylori using urease breath test. Avicenna Journal of Phytomedicine. 2016;6(5):495.

23. Chauhan NB, Sandoval J. Amelioration of early cognitive deficits by aged garlic extract in Alzheimer's transgenic mice. Phytother Res. 2007;21:629-40.

24. Ushijima M, Sumioka I, Kakimoto M, Yokoyama K, Uda N, Matsuura $\mathrm{H}$, et al. Effect of garlic and garlic preparations on physiological and psychological stress in mice. Phytotherapy

Research. 1997;11(3):226-230.

25. Jeong $Y Y$, Ryu JH, Shin JH, Kang MJ, Kang JR, Han J, et al. Comparison of antioxidant and anti-inflammatory effects between fresh and aged black garlic extracts. Molecules. 2016;21(4):430.

26. Mathew BC, Biju RS. Neuroprotective effects of garlic a review. Libyan Journal of Medicine. 2008;3(1):23-33.

27. Lee BH, Kim YK. The roles of BDNF in the pathophysiology of major depression and in antidepressant treatment. Psychiatry investigation. 2010;7(4):231-235.

28. Abbott $R$, Whear $R$, Nikolaou $V$, Bethel $A$, Coon JT, Stein K, et al. Tumour necrosis factor- $\alpha$ inhibitor therapy in chronic physical illness: A systematic review and meta-analysis of the effect on depression and anxiety. Journal of psychosomatic research. 2015;79(3):175-184.

29. Ramadan KS, Farid AEH, Almarashi RMM. Antidepressant-like effects of aqueous extract of salvadorapersica in rat model of depression. J Diabetes Metab. 2016;7(697):2.

30. Olsson I, Dahlborn K. Improving housing conditions for laboratory mice: A review of environmental enrichment. Laboratory Animals. 2000;36:243-270.

31. Escorihuela RM, Tobena A, FernandezTeruel A. Environmental enrichment reverses the detrimental action of early inconsistent stimulation and increases the beneficial effects of postnatal handling on shuttlebox learning in adult rats. Behav. Brain Res. 1994;61:169-173.

32. Klein SL, Lambert KG, Durr D, Schaefer T, Waring RE. Influence of environmental enrichment and sex on predator stress response in rats. Physiol. Behav. 1994;56:291-297.

33. Coe CL, Lubach GR, Karaszewski JW, Ershler WB. Prenatal endocrine activation alters postnatal cellular immunity in infant monkeys. Brain Behav. Immun. 1996;10:221-234.

34. Kingston SG, Hoffman-Goetz L. Effect of environmental enrichment and housing density on immune system reactivity to 
acute exercise stress. Physiol. Behav. 1996;60:145-150.

35. Brown J, Cooper-Kuhn C, Kempermann G, Van Praag $\mathrm{H}$, Winkler J, Gage $\mathrm{F}$, et al. Enriched environment and physical activity stimulate hippocampal but not olfactory bulb neurogenesis. Eur. J. Neurosci. 2003;17:2042-2046.

36. Zhang L, Zhang J, Sun H, Liu H, Yang Y, Yao Z. Exposure to enriched environment restores the mRNA expression of mineralocorticoid and glucocorticoid receptors in the hippocampus and ameliorates depressive-like symptoms in chronically stressed rats. Current neurovascular research. 2011;8(4):286293.

37. Toudert N, Zaiter A, Djilani SE, Dada N, Djilani A, Dicko A. Impact of methanolwater ratio of leaf and root extracts of ampelodesma mauritanicaon the antioxidant activity, and effect of different solvent extraction on phenolic compounds quantification. Acta

Sci. Nutr. Health. 2017;1:3-7.

38. Chinedu E, Arome D, Ameh FS. A new method for determining acute toxicity in animal models. Toxicology international. 2013;20(3):224.

39. Roghini R, Vijayalakshmi K. Phytochemical screening, quantitative analysis of flavonoids and minerals in ethanolic extract of Citrus paradisi. Int J Pharm Sci \& Res. 2018;9(11):4859-64.

40. Renner M, Rosenzweig M. Social interactions among rats housed in grouped and enriched conditions. Dev. Psychobiol.1986;19:303-313.

41. Laviola G, Rea M, Morley-Fletcher S, Di Carlo S, Bacosi A, De Simone R, et al. Beneficial effects of enriched environment on adolescent rats from stressed pregnancies. European Journal of Neuroscience. 2004;20(6):16551664.

42. Porsolt RD, Le Pichon $M$, Jalfre $M$. Depression: A new animal model sensitive to antidepressant treatments. Nature. 1977;266:730-732.

43. Steru L, Chermat R, Thierry B, Simon P. The tail suspension test: a new method for screening antidepressants in mice. Psychopharmacology. 1985;85: 367-370.

44. Potdar HV, Kibile SJ. Evaluation of antidepressant-like effect of Citrus maxima leaves in animal models of depression. Iranian journal of basic medical sciences. 2011;14(5):478-483.

45. Serchov T, van Calker D, Biber K. Sucrose preference test to measure anhedonic behaviour in mice. Bio-protocol. 2016;6(19):1958.

46. Kameshwaran S, Senthilkumar R, Thenmozhi S, Dhanalakshmi M. Wound healing potential of ethanolic extract of tecoma stans flowers in rats. Pharmacologia. 2014;5(6):215-221.

47. Dhingra D, Kumar V. Evidences for the involvement of monoaminergic and GABAergic systems in antidepressant-like activity of garlic extract in mice. Indian journal of pharmacology. 2008;40(4):175.

48. Bahi A, Dreyer JL. Environmental enrichment decreases chronic psychosocial stress-impaired extinction and reinstatement of ethanol conditioned place preference in C57BL/6 male mice. Psychopharmacology. 2020;237(3)7 07-721.

49. Hutchinson KM, McLaughlin KJ, Wright RL, Ortiz JB, Anouti DP, Mika A, et al. Environmental enrichment protects against the effects of chronic stress on cognitive and morphological measures of hippocampal integrity. Neurobiology of learning and memory. 2012;97(2):250-260.

50. Huang YJ, Lu KH, Lin YE, Panyod S, Wu HY, Chang WT, et al. Garlic essential oil mediates acute and chronic mild stressinduced depression in rats via modulation of monoaminergic neurotransmission and brain-derived neurotrophic factor levels. Food \& function. 2019;10(12):80948105.

51. Kaptan Z, Dar KA, Kapucu A, Bulut H, Üzüm G. Effect of enriched environment and predictable chronic stress on spatial memory in adolescent rats: Predominant expression of BDNF, nNOS, and interestingly malondialdehyde in the right hippocampus. Brain research. 2019;1721:146326.

52. Fatima $M$, Srivastav $\mathrm{S}$, Ahmad $\mathrm{MH}$, Mondal AC. Effects of chronic unpredictable mild stress induced prenatal stress on neurodevelopment of neonates: Role of GSK-3 $\beta$. Scientific reports. 2019;9(1):1-13.

53. Duda W, Curzytek K, Kubera M, Iciek M, Kowalczyk-Pachel D, Bilska-Wilkosz A, et al. The effect of chronic mild stress and imipramine on the markers of oxidative stress and antioxidant 
system in rat liver. Neurotoxicity research. 2016;30(2):173-184.

54. Muhammad MS, Magaji RA, Mohammed A, Isa AS, Magaji MG. Effect of resveratrol and environmental enrichment on biomarkers of oxidative stress in young healthy mice. Metabolic brain disease. 2017;32(1):163-170.

55. Sequeira-Cordero A, Mora-Gallegos A, Cuenca-Berger $\mathrm{P}$, Fornaguera-Trías $\mathrm{J}$. Individual differences in the forced swimming test and neurochemical kinetics in the rat brain. Physiology \& behaviour. 2014;128:60-69.

56. Seong HH, Park JM, Kim YJ. Antidepressive effects of environmental enrichment in chronic stress-induced depression in rats. Biological research for nursing. 2018;20(1):40-48.
57. Marcon M, Mocelin R, Benvenutti R, Costa $T$, Herrmann AP, de Oliveira $\mathrm{DL}$, et al. Environmental enrichment modulates the response to chronic stress in zebrafish. Journal of Experimental Biology. 2018;221(4).

58. López-López AL, Jaime HB, Villanueva MDCE, Padilla MB, Palacios GV, Aguilar FJA. Chronic unpredictable mild stress generates oxidative stress and systemic inflammation in rats. Physiology \& behaviour. 2016;161:15-23.

59. Liu YN, Peng YL, Wu TY, Zhang Y, Lian YJ, Yang YY, et al. TNFa mediates stressinduced depression by upregulating indoleamine 2, 3-dioxygenase in a mouse model of unpredictable chronic mild stress. European cytokine network. 2015;26(1):15-25.

(c) 2021 Mshelia et al.; This is an Open Access article distributed under the terms of the Creative Commons Attribution License (http://creativecommons.org/licenses/by/4.0), which permits unrestricted use, distribution, and reproduction in any medium, provided the original work is properly cited.

Peer-review history:

The peer review history for this paper can be accessed here: http://www.sdiarticle4.com/review-history/65871 